revisa la "Poesía nueva en México". Nada de lo que aquí se examina agrega cosa alguna a su conocida introducción a la antología Palabra nueva, dos décadas de poesía en México, que publicó con Premiá en 1981. Por cierto, el artículo que integra el libro aparece fechado en 1961, año en que Cohen tenía apenas ocho de edad. Más que precocidad inigualable, se trata, seguramente, de una más de las erratas descomunales de que está plagado el libro. Lugar de encuentro evidencia un lamentable desencuentro con toda pulcritud y aliño editoriales, las erratas desbordan el libro y se ensañan, sobre todo, con el aparato crítico que resulta inútil. Evidente es también el atraso de la información consignada en las fichas biobibliográficas de los autores. Sin embargo,en una nueva edición que subsane estos descuidos, llegará a constituirse en un libro de consulta importante por el criterio que rige la mayor parte del proyecto.

University of Pittsburgh

\title{
SAMUEL GORDON
}

GUSTAVO PELLON: José Lezama Lima's Joyful Vision. Austin: Texas Press, 1989. EMILIO BEJEL: José Lezama Lima, Poet of the Image. Gainsville: Florida, 1990.

$\mathrm{Al}$ leer estos dos recientes estudios se hace evidente que la aventura espiritual que emprendiera José Lezama Lima, desde los orígenes de la sensibilidad poética hasta su fase creadora, ha de resultar quizás una contribución mayor que sus poemas o su monumental novela Paradiso. Esta aventura es el tema medular de casi toda su obra. Si se permitiese la paráfrasis, el desarrollo de su sistema poético pudiera equipararse a un manual de método, al estilo del que Stanislavsky hizo para el teatro: El poeta se prepara, pues para llegar al acto creador ha de llegarse a lo más íntimo del ser. Con celo misionero, Lezama se impuso la tarea de crear una nueva tradición poética, en busca de una nueva aristocracia que nada tenía que ver con el dinero; muy al contrario, exigía los mayores sacrificios. La poesía era la tierra prometida, el único paraíso posible, pero no bastaba, desde luego, con leer. Había que escribir y escribir. Así creó un buen número de conversos en su pequeña isla, y comenzó un diálogo, que todavia continúa, con insospechados rincones del mundo. Pero este diálogo no es fácil (Lezama nunca intentó que lo fuera). Su temperamento barroco lo impulsó a mezclar anticartesianamente estilos, tradiciones e ideas filosóficas de muy distintas épocas con sus propias vivencias oblicuas. Las conexiones que se multiplican y las profusas alusiones, a veces imprecisas por provenir de la memoria y no de paciente labor de "archivero", según su expresión, no hacen fácil la tarea. Además, Lezama desarrolló un léxico, con sus propios ecos y significados (el súbito, la fijeza, la hipertelia, hesicástico, la sobrenaturaleza). Se presta, por tanto su obra a la interpretación múltiple o parcial, en ambos sentidos de la palabra, y tenemos necesidad de recurrir a estudios como los que 
hoy nos ocupan, que ayuden a dilucidar el fundamento ideológico de su sistema poético y analicen cómo y hasta qué punto logró llevarlo a la práctica en su obra.

La mayor contribución de Gustavo Pellón, a mi parecer, consiste en el tratamiento de tres puntos aislados: posibles causas de la recepción negativa de la obra lezamiana, en particular de Paradiso, la participación de Julio Cortázar en lainclusión de Lezama en el llamado boom; y, en cierto modo, la identificación de Lezama con la visión artística de un pintor, Henri Rousseau.

Pellón sostiene que al privilegiar la descripción sobre la narración, Lezama crea una falta de balance, considerada por algunos como un fallo y que, además, a cualquiera que favorezca la estética realista pueden fácilmente ofenderle los excesos de Paradiso. Comenta las objeciones de J.M.Alonso y de Julio RodriguezLuis, mientras que defiende, siguiendo a Emir Rodríguez Monegal y en parte a Severo Sarduy, la ventaja de aplicar el modelo dialógico bahktiniano para el estudio de esta novela. En el segundo capítulo, Pellón analiza la estética del exceso: la novela como fibroma, tema que ya había desarrollado con anterioridad a este libro. Como metáfora para las excrecencias arbóreas lezamianas no es agradable, pero resulta útil para analizar algunos aspectos del modus operandi del escritor. Según indica Pellón en el tercer capítulo, Lezama considera que los mayores peligros que acechan al poeta son la homosexualidad, la locura y el suicidio, e ilustra con pasajes de Paradiso el por fin logrado estado andrógino y creador de José Cemí, su personaje central y alter ego. Ha de decirse, de paso, que en estos capítulos y los que le siguen hay una superabundancia de citas, todas bien escogidas y documentadas. En el último capítulo, número seis, entra el autor en el tema que da título al libro: Lezama y Rousseau o el arte inocente y alegre. Para facilitar la comparación, se incluyen reproducciones de cinco cuadros del pintor francés (¿Es Lezama un primitivo o un primitivista?, se pregunta).

Personalmente, debo confesar que soy parcial a la idea de considerar jubilosa la visión de Lezama, como sugiere el título de este estudio. Véanse a este respecto mis notas "Lezama Lima: Contradicción y júbilo de la poesía", Chasqui (mayo 1979): 83-88; reseña de Fragmentos a su imán, Cuadernos

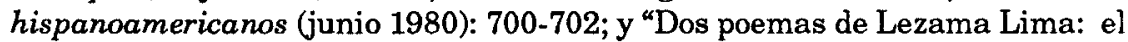
primero y el postrero", Memorias del Coloquio Internacional sobre la obra de José Lezama Lima, 1982, Universidad de Poitiers (Madrid: Editorial Fundamentos, 1984) Vol. I, 143-155. Por este motivo, siento que la visión jubilosa del título no haya sido el hilo central de los comentarios de Gustavo Pellón, que tienen, sin embargo, aciertos indiscutibles. Uno de ellos es elevar la obra del contexto hispánico a conceptos de literatura universal y teorías críticas de actualidad.

El volumen de Emilio Bejel está ilustrado atractivamente por Vicente Dopico a la manera de Portocarrero en la edición Era de Paradiso. El primer capítulo, "Rhapsody for an Absent Nature", sirve de introducción no sólo al libro, sino también para quien no haya entrado todavia en la órbita lezamiana. Este 
capítulo toca puntos importantes en forma simple y coherente. Subraya, además, las relaciones entre Lezama y otros poetas y escritores, principalmente en el marco cultural cubano-Heredia, Martí y Mañach-así como la elevación de la imaginación poética sobre la razón conceptual, visión que Lezama asimiló de Dante. Bejel ilustra su discusión teórica con el poema "Rapsodia para el Mulo", del cual ofrece también una traducción en prosa al inglés. La selección de este poema para iluminar la visión positiva de Lezama frente a la función del lenguaje y de la poesía resulta muy acertada.

El capítulo designado como segundo, continuando las ideas del anterior, comenta la importancia de la imagen para Lezama, dado el fallo de la naturaleza y de la razón. Se discute la influencia de Vico, de filósofos alemanes (Nietzsche, Heidegger), poetas franceses (Mallarmé, Valery), y figuras notables del catolicismo (San Pablo, San Agustín y Sor Juana). Ilustra los puntos tratados, como en el capítulo anterior, con una explicación de texto: "Muerte de Narciso". El material está bien organizado y, dadas las circunstancias, explicado con claridad. Estos tres primeros capítulos constituyen, a mi entender, los más logrados del libro.

El capítulo siguiente discute el poema como un acto erótico que aspira finalmente a trascender el deseo, tomando por ejemplo "Aventuras sigilosas". También comenta detalles muy específicos de la trama de Paradiso. Aunque tiene aciertos e intuiciones valiosas, puede hacerse difícil de seguir para aquellos lectores que no hayan leído Paradiso recientemente. Los iniciados encontrarán ideas interesantes y con frecuencia iluminadoras. El capítulo cuarto, "Después de la tormenta, continúa con Oppiano Licario, y para terminar, en "Las nuevas costas de Tauro" comenta el neobarroco y lo real-maravilloso 0 , lo que para él parece ser lo mismo, el realismo mágico. Escoge acertadamente como ejemplo La expresión americana. Hubiera sido interesante añadir un capítulo más que comentara la esencia de su sensibilidad poética, dejando atrás sus excesos verbales, para ilustrar con Fragmentos a su imán, obra importante escrita durante los últimos años de Lezama cuando careció del apoyo del gobierno revolucionario cubano y se vio incapacitado de participar en actividades culturales dentro y fuera de su país. A este respecto, Bejel admite este hecho (12) y menciona como referencia el trabajo que Armando Alvarez Bravo leyó en el Coloquio Internacional de la Universidad de Poitiers sobre la obra de Lezama. Aduce que hay opiniones contrarias, y ofrece entonces algunos comentarios y una lista bibliográfica (véanse notas, 149-150) que incluye en su mayoría a escritores todavía en Cuba.

Los tópicos de cada capítulo y las obras que le sirvieron para ilustrar los puntos teóricos han sido escogidos y tratados por Bejel con cuidado. Puede verse que éste no es un estudio preparado con premura para su publicación, sino un tema que ha apasionado al autor por largo tiempo. Y ésa es una de las características del poeta cubano José Lezama Lima: llegar a conocerlo no es fácil, pero pasado el período de iniciación, demanda lealtad y respeto y, lo más 
esencial, ejerce la magia de impulsarnos a aspiraciones más altas y a liberarnos a emprender tareas mayores que nuestras fuerzas.

New York

DOLORES M. KOCH

OSCAR BONIFAZ: Remembering Rosario. A Personal Glimpse into the Life and Works of Rosario Castellanos. Translated and Edited by Myralyn F. Allgood. Scripta Humanística, USA, 1990.

La celebración del décimo sexto aniversario de la muerte de Rosario Castellanos en San Cristóbal de las Casas (Chiapas) ha dado lugar a consideraciones significativas: Rosario sigue siendo poco conocida y leída en México .... Apenas se empieza a reconocerla como "buena" poeta .... Su compromiso social (el feminismo en particular) se discute todavia .... En tanto intelectual, Castellanos es más reconocida y valorada en el extranjero que en su propio país ....

La iniciativa de Myralyn F. Allgood por lo tanto, no sólo confirma la última consideración, que en resumidas cuentas sintetiza bien las primeras, sino que marca los múltiples esfuerzos que se realizan en los Estados Unidos para hacer justicia a Rosario Castellanos y a su producción literaria.

Remembering Rosario es la traducción al inglés de la biografía de Castellanos escrita por Oscar Bonifaz. Rosario (1984) es un libro de acceso difícil, desconocido hasta en México, pero sobre todo es un libro controvertido. Con su muerte, Rosario Castellanos se convirtió, no sólo en "parque", sino también en "bandera" que muchos, por motivos distintos y con justificaciones diversas, quisieran llevar. Sin embargo, entre todas esas voces que reivindican a Castellanos, el testimonio de Oscar Bonifaz sobresale por lo que recalca Myralyn:

No oneknew Rosario Castellanos more closely, over a longer period of time, than Oscar Bonifaz. Perhaps it is for this reason that his little biography of her has such warmth, such charm. It is a tribute, written with tenderness and affection in an intimate, conversational style, to a lifelong companion whom he cherished as a friend and respected as a creative artist. An astute literary talent in his own right, Bonifaz shared with Castellanos a lifetime of experiences in the cultural context of Chiapas and is thus her ideal biographer (Remembering, 9).

Remembering Rosario es un testimonio clave para los que desean conocer "íntimamente" a Castellanos, porque registra informaciones importantes en cuanto a su vida personal y a su trayectoria literaria. En la exposición cronológica de dichas informaciones se puede distinguir dos períodos, dos etapas vinculadas entre sí: 